\title{
DESENVOLVIMENTO DE UM SOFTWARE DIDÁTICO PARA SÍNTESE DE REDES DE TROCADORES DE CALOR UTILIZANDO ANÁLISE PINCH
}

\author{
M. O. BATISTA ${ }^{1}$, M. A. S. S. RAVAGNANI ${ }^{1}$, L. V. PAVÃO ${ }^{1}$, C. B. MIRANDA ${ }^{1}$ \\ ${ }^{1}$ Universidade Estadual de Maringá, Departamento de Engenharia Química \\ E-mail para contato: mari_oliveirabatista@hotmail.com
}

\begin{abstract}
RESUMO - Hoje em dia há uma grande preocupação com o consumo energético dos processos industriais visando o reaproveitamento de energia por meio de redes de trocadores de calor (RTC) e a consequente diminuição do consumo de utilidades. Durante a graduação, os discentes se deparam com várias disciplinas e problemas envolvendo RTC, para isso um dos métodos desenvolvidos para a síntese dessas redes foi a Análise Pinch, que pode ser realizada com o auxílio de softwares. Dessa forma, criou-se um programa utilizando o ambiente do Matlab com uma interface bastante clara a fim de deixar os estudantes no controle de todos os estágios do projeto. Testes foram realizados com casos da literatura a fim de comprovar a viabilidade de sua utilização. Portanto, tem-se uma expectativa otimista em relação ao uso do programa em disciplinas, pois esse melhoraria a eficiência do curso.
\end{abstract}

\section{INTRODUÇÃO}

Com o aumento do custo energético, principalmente nas indústrias, surgiu-se uma crescente preocupação em se otimizar e minimizar o uso de energia. Para isso, várias metodologias de integração energética têm sido criadas e aperfeiçoadas, porém uma das mais eficientes, a qual será tratada neste trabalho, é a Análise Pinch. Esse método é uma junção de conceitos da primeira e segunda lei da termodinâmica com algumas regras heurísticas para a escolha dos pares de correntes de processo que irão trocar calor. Tal análise baseia-se em dividir a rede em subredes após a identificação do ponto Pinch e realizar o balanço de energia em cada uma destas. Além disso, é possível obter a máxima recuperação de energia no processo, o número mínimo de equipamentos de troca térmica, a área mínima e o custo mínimo de capital e energia da rede (MARTÍN; MATO, 2008).

Os cálculos necessários para a Análise Pinch são relativamente simples e podem ser realizados manualmente para exemplos com poucas correntes. Porém, para exemplos com grandes quantidades de correntes, como em problemas de escala real de uma indústria, eles se tornam demorados e monótonos. Logo, é recomendado o uso de programas computacionais que realizem estes cálculos automaticamente e forneçam ao usuário apenas a parte de síntese e otimização da RTC. O programa desenvolvido permite, ainda, o controle total do projeto pelo usuário e ajuda a identificar os parâmetros do processo que estão dificultando a economia de energia.

Muitas vezes, o conteúdo ministrado em salas de aulas envolvendo síntese de RTC 
acaba sendo maçante e cansativo para os alunos, pois envolve, sobretudo, muitos cálculos. A fim de buscar maior interesse dos discentes, assim como facilitar a resolução de problemas envolvendo RTC, desenvolveu-se o software por meio do ambiente de programação Matlab, com uma interface bastante clara e de fácil entendimento pelo usuário para que este concentrasse seus esforços em aprender os conceitos do método Pinch e não em aprender como usar o programa em si. Ele é chamado MPinch, em que o "M" remete ao ambiente de programação Matlab e à Universidade Estadual de Maringá (UEM).

O programa começou a ser desenvolvido em Setembro de 2013 e passou por uma fase de testes em março de 2014 com os alunos do quinto ano de Engenharia Química da UEM que cursavam a disciplina de Projetos e Processos Industriais. Devido à ótima aceitação e com o posterior aperfeiçoamento da habilidade e interface do programa, têm-se como objetivo agora o emprego de fato deste em todas as disciplinas que envolverem principalmente a integração energética.

\section{APLICAÇÃO E EXEMPLO DA LITERATURA}

A fim de demonstrar a aplicação do programa será apresentado um exemplo retirado de SMITH (2005) conforme disposto na Tabela 1, se trata de um problema envolvendo três correntes quentes, duas frias e $\Delta T_{\min }=10^{\circ} \mathrm{C}$, o qual deve ser preenchido na parte central da tela inicial do programa MPinch, como mostra a Figura 1.

Tabela 1 - Dados do exemplo.

\begin{tabular}{llll}
\hline Corrente & $\mathrm{T}_{\text {entra }}\left({ }^{\circ} \mathrm{C}\right)$ & $\mathrm{T}_{\text {sai }}\left({ }^{\circ} \mathrm{C}\right)$ & $\mathrm{CP}\left(\mathrm{MW} /{ }^{\circ} \mathrm{C}\right)$ \\
\hline 1 & 200 & 100 & 0,4 \\
2 & 200 & 100 & 0,2 \\
3 & 150 & 60 & 1,2 \\
4 & 50 & 140 & 1,1 \\
5 & 80 & 120 & 2,4 \\
\hline
\end{tabular}

O software tem a aparência inicial conforme mostrado na Figura 1, quando totalmente inicializado. Assim, o procedimento foi iniciado com a entrada dos dados das correntes no painel do canto superior esquerdo, digitando os valores de temperatura e CP (Capacidade Térmica), onde para cada corrente e clicando em "Adicionar Correntes". Em caso de erro de digitação, seleciona-se a corrente inserida incorretamente, preenchem-se os campos corretamente e clica-se em "Modificar". A corrente também pode ser excluída, clicando-se em "Remover". Além disso, o utilizador poderá salvar estes dados em uma planilha do Microsoft Excel, clicando em "Arquivo" e em seguida "Salvar Correntes".

Figura 1 - Interface do MPinch totalmente inicializada. 

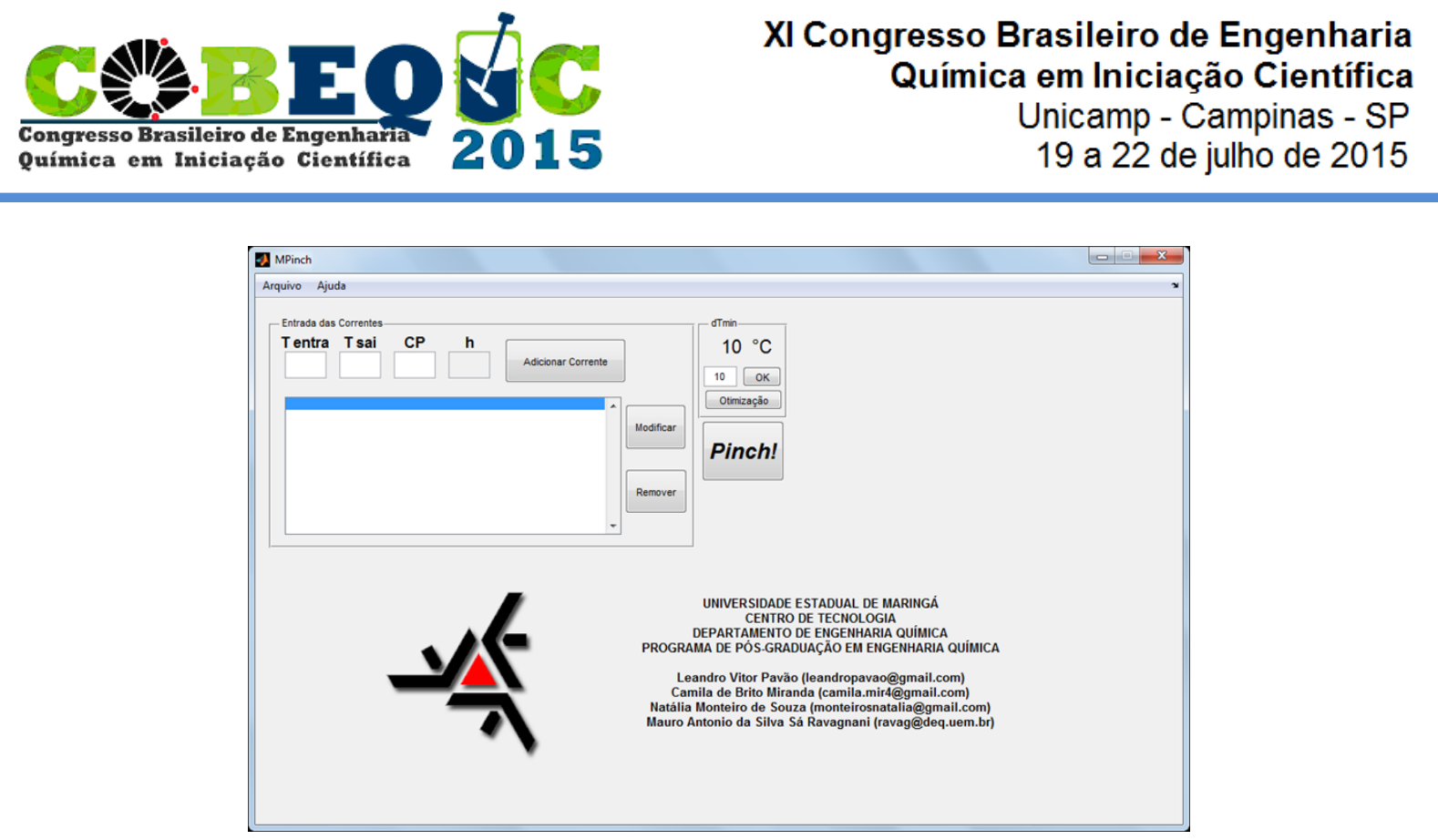

Terminada a etapa de entrada dos dados, clicando em "Pinch!", o acadêmico poderá visualizar todos os passos do Procedimento Tabular de Linnhoff, conforme visto na Figura 2: o diagrama auxiliar dos balanços de energia; as cascatas energéticas e o diagrama $\mathrm{TH}$, com as quantidades mínimas de calor a serem trocadas com utilidades quentes e frias, $(30 \mathrm{~kW}$ e 3 $\mathrm{kW}$, respectivamente, para o problema) e as temperaturas do ponto de estrangulamento (neste exemplo, $80{ }^{\circ} \mathrm{C}$ para correntes frias e $90{ }^{\circ} \mathrm{C}$ para correntes quentes), todos precisamente condizentes a resultados da literatura. Os diagramas de balanço e TH podem ser exportados para o ambiente de edição de figuras do Matlab ao clicar em "Exportar". Neste, o usuário pode, por exemplo, adicionar anotações ao desenho e salvá-lo em diversos formatos, como JPG, PNG, ou mesmo PDF.

Figura 2 - Passos do Procedimento Tabular de Linnhoff, após o clique em "Pinch!".

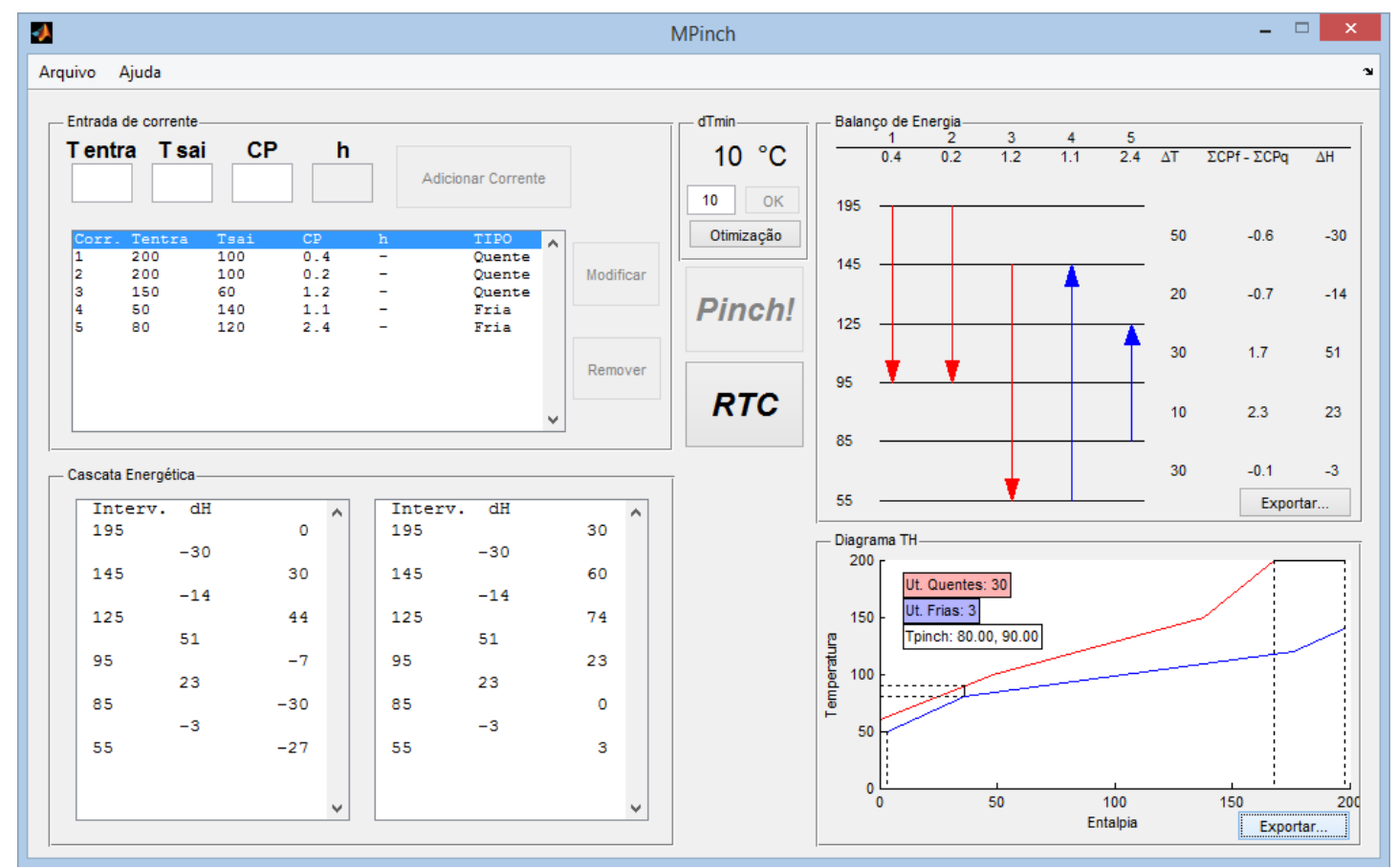

Ao clicar em "RTC", o aluno pode visualizar o diagrama de grade da rede à direita. 
Inicialmente a visualização será acima do Pinch, podendo ser alterada nos botões da parte inferior do painel. O diagrama de rede também pode ser expandido, para melhor visualização, clicando em "Expandir RTC".

Sendo assim, segundo RAVAGNANI \& CABALLERO (2012) o problema acima do Pinch, do exemplo analisado, é relativamente simples, porém se faz necessária a divisão de uma corrente, pois o número de correntes que sai é menor que o número de correntes que entram no Pinch o que viola uma das regras heurísticas da metodologia. Dessa forma, faz-se necessário a divisão de alguma das correntes que sai, de preferência a que possui maior capacidade calorífica, a qual é a corrente fria cinco no exemplo em questão. Para esta divisão, deve-se clicar em "Dividir Corr." onde o usuário deverá escolher em quantas correntes a mesma será divida e posteriormente a porcentagem de cada $\mathrm{CP}$, o valor de cada $\mathrm{CP}$ em si ou a quantidade de calor de cada uma dessas e clicar em "ok".

A alocação dos trocadores de calor é feita clicando no botão "Adc. Trocador". Ao fazer o clique, uma cruz característica do programa Matlab aparece e o usuário deverá clicar nas duas correntes as quais deseja trocar calor. Horizontalmente, o trocador ficará posicionado no diagrama na coordenada em que ele realizou o primeiro clique. Após selecionar as duas correntes que trocarão calor, o programa, conforme a metodologia Pinch, calcula o trocador sempre do ponto de estrangulamento para as extremidades. Ou seja, neste trocador, acima do Pinch, têm-se as temperaturas quente de saída e fria de entrada. A primeira troca térmica escolhida é o par de correntes 1 e 4 . O algoritmo seleciona o menor calor entre as duas correntes, neste caso, os $40 \mathrm{~kW}$ da corrente quente 1, e realiza o balanço de energia, calculando as temperaturas quente de entrada e fria de saída, além do calor remanescente na corrente fria 4. Os valores recalculados dos calores são então mostrados ao lado de cada corrente.

Por padrão, o programa utiliza todo o calor disponível para troca. Entretanto, o usuário tem a possibilidade de trocar menos calor em um equipamento, dependendo das necessidades de sua RTC. Isto é possível no painel "Modificar Trocador", disposto na Figura 3, que aparece ao lado esquerdo sempre que uma troca é realizada. Este painel exibe as temperaturas dos terminais do trocador e um gráfico de Temperatura x Comprimento do trocador de calor. O usuário pode modificar, no trocador em questão, Tqe ou Tfs e clicar em "Recalcular", para verificar o calor trocado. Caso esteja de acordo com a mudança, clicando em "OK", os valores são passados para a RTC. O mesmo painel pode ser acessado clicando em "Editar Trocador", e em seguida, selecionando o trocador desejado para a edição. No trocador atual, estas opções não foram utilizadas.

Prosseguindo com a síntese da rede, alocou-se um trocador entre as correntes 2 e 5-1 e entre 3 e 5-2, restando um calor de $24 \mathrm{~kW}$ na corrente quente 3. Para esgotar esta corrente, aloca-se um novo trocador entre a mesma e a corrente fria 5-1. Os calores restantes de $26 \mathrm{~kW}$, na corrente fria 4 , e de $4 \mathrm{~kW}$ na corrente fria 5-1, estão de acordo com o valor determinado no Procedimento Tabular de Linnhoff para a necessidade de utilidades quentes. Clicando em "Util. Quente" aparece novamente a cruz para selecionar a corrente que precisa ser esgotada com utilidade. Selecionou-se, então, a extremidade das correntes 4 e 5-1, esgotando assim toda a necessidade de calor das correntes frias acima do Pinch. As Utilidades, da mesma forma que os trocadores, podem ser alteradas no painel "Modificar Trocador". 


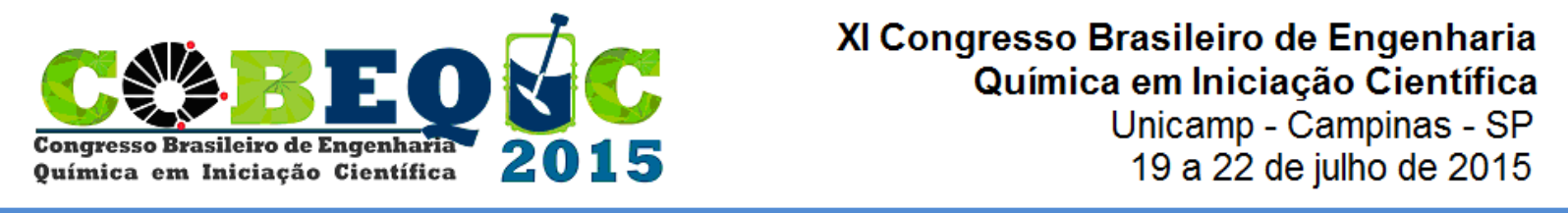

Passou-se então para as correntes abaixo do Pinch. O diagrama mostra uma corrente quente e uma fria. Pode-se esgotar a necessidade desta corrente fria $4 \mathrm{com}$ um trocador, e em seguida, alocar uma utilidade fria para esgotar o calor restante na corrente 3. A rede sintetizada é mostrada na Figura 4, obtida ao clicar-se em "Toda a Rede".

Figura 3 - Painel de edição de trocadores.

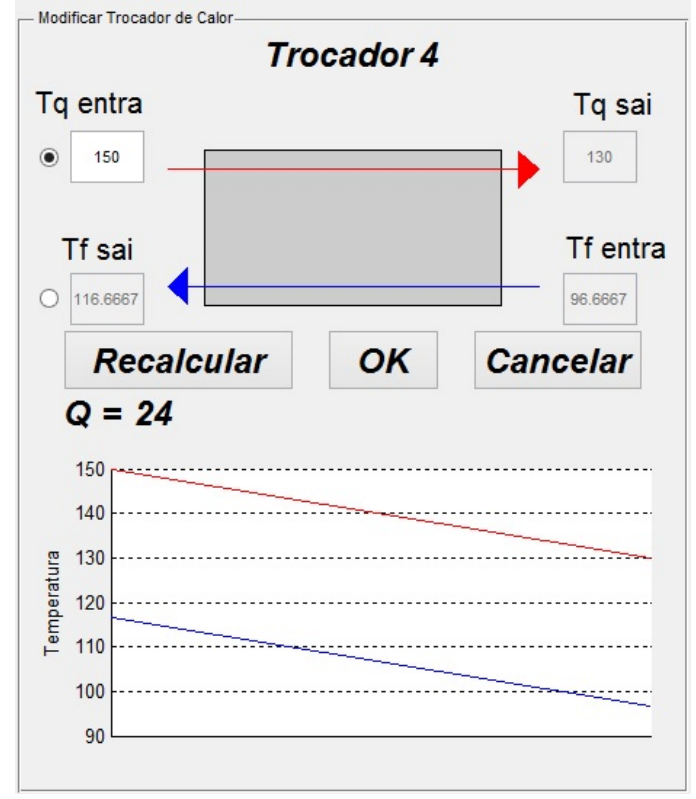

Figura 4 - Rede sintetizada para o exemplo.

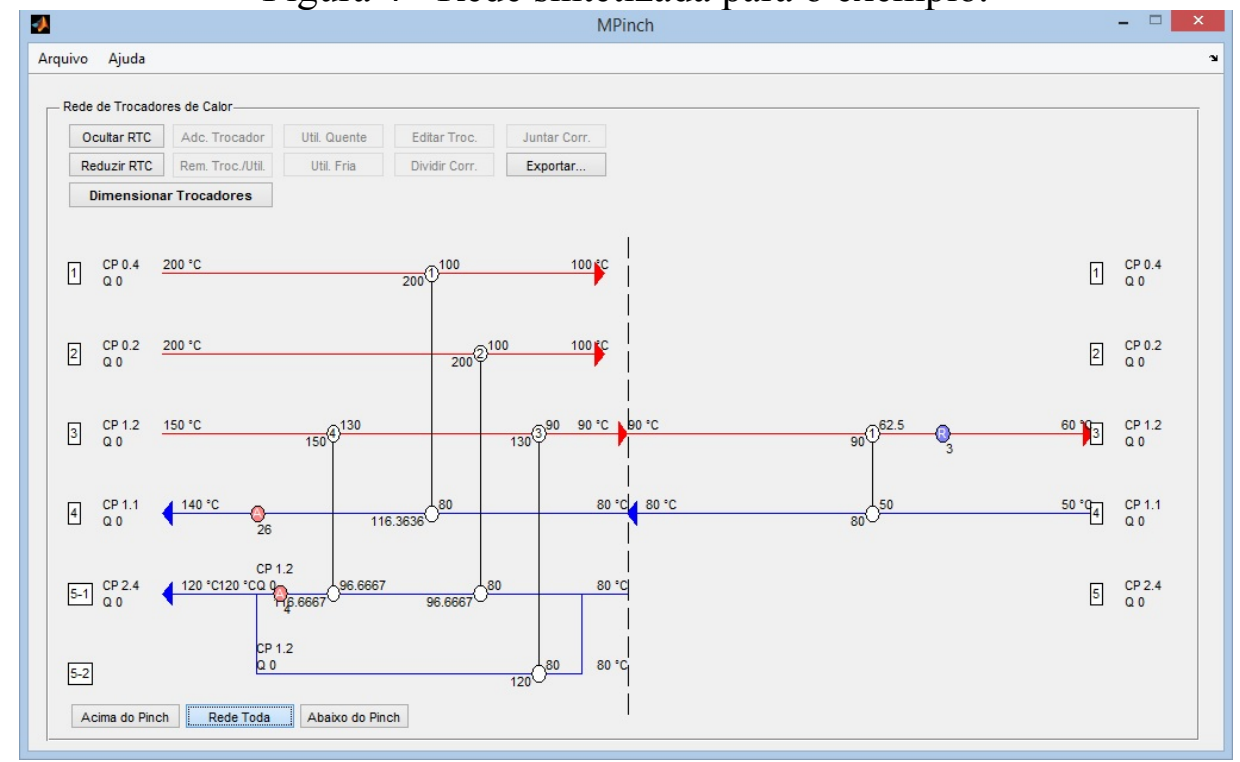

O estudante pode, também, exportar os diagramas para o ambiente de edição de figuras do Matlab, clicando em "Exportar". Caso queira salvar seus resultados, a opção aparece ao clicar em "Arquivo" e em seguida "Salvar Projeto". Estes dados são salvos em um arquivo com a extensão ".mat" pelo próprio Matlab.

\section{CONCLUSÕES}


O software MPinch foi desenvolvido e aplicado com sucesso como forma de auxílio ao aprendizado da Análise Pinch a uma turma de quinto ano do curso de graduação em Engenharia Química, usando casos da literatura. Os cálculos, muitas vezes monótonos para redes com muitas correntes, foram realizados mais rapidamente, de forma totalmente interativa e dinâmica, permitindo aos alunos realizar a síntese da RTC de forma mais eficaz. É possível ver nas RTC sintetizadas que os resultados foram promissores, o que torna possível a aplicação futura em novas turmas durante o ensino de integração energética, assunto de extrema importância na atualidade, e que a fixação de seu conhecimento torna-se cada vez mais necessário para os novos profissionais.

\section{REFERÊNCIAS}

LINNHOFF, B.; TOWSEND, D. W.; BOLAND, D.; HEWITT, G. F.; THOMAS, B. E. A.; GUY, A. R.; MARSLAND, R. H. A User Guide on Process Integration for the Efficient Use of Energy. Rugby: The Institution of Chemical Engineers, 1982.

LINNHOFF, B.; AHMAD, S. Cost optimum heat exchanger networks-1. Minimum energy and capital using simple models for capital cost. Comput. Chem. Eng., v. 14, n. 7, p. 729-750, 1990.

MARTÍN, A.; MATO, F. A. Hint: An educational software for heat exchanger network design with the pinch method. Educ. Chem. Eng., v. 3, p. e6-e14, 2008.

SMITH, R. Chemical process design and integration. Chichester: Wiley, 2005.

RAVAGNANI, M. A. S. S.; CABALLERO SUÁREZ, J. A. Redes de Cambiadores de Calor. Alicante: Editora de la Universidad de Alicante, 2012. 